sciendo Порівняльна професійна педагогіка 8(2)/2018 Comparative Professional Pedagogy 8(2)/2018

DOI: $10.2478 /$ rpp-2018-0033

Postgraduate Student, VIKTORIA OKHREI

Khmelnytskyi Basic Medical College

Address: 37 Proskurivska St., Khmelnytskyi, 29000 Ukraine

E-mail: 0683368275zz@gmail.com

\title{
ENHANCEMENT OF QUALITATIVE PHARMACISTS' TRAINING: CANADIAN EXPERIENCE
}

\begin{abstract}
The necessity for the development and restructuring of pharmacists' training programs to correspond their increased practical role in society has been substantiated. It has been determined that Canada for the last decade has introduced a lot of changes concerning enhancement of pharmacists' training, among which the following are of special interest: fulfillment of the training with a strict accordance with the accreditation standards, selective admission to colleges of pharmacists, assessment of students' critical thinking and teaching methods, improvement of courses content delivery, interprofessional cooperation, development of practical experimental education, clinical rotations programs, mentoring programs etc. It has been defined that accreditation standards for pharmacists' training in Canada reflect professional and educational attributes that intend to develop practicing, clinical, patient-focused pharmacists. They outline that pharmacy education of high quality depends on multiple components, including general knowledge, basic and professional sciences, and professional practice experience. The pharmacy curriculum is expected to embrace the scope of contemporary practice responsibilities as well as emerging roles that ensure the rational and safe use of drugs in the individualized care of patients. In the research it has been found out that admission of students to pharmacy colleges is organized so that to select students possessing inborn leadership skills and those of decision making. A number of techniques and tests for admission have been analyzed. Teaching strategies of theory in practice, critical thinking, clinical reasoning, inference and decision-making, which are widely used in Canadian pharmacy education, have been characterized. It has been stated that professional cooperation between medical and pharmacy students in Canada is an approach to health protection aimed at the patient and is team-based. It underlines one's strengths and skills related to health care provision and should be taken into account. Clinical experimental rotations are one more approach that should be taken into consideration by Ukrainian educators and legislators (early involvement of students to establishments for taking care of patients and rotations of both senior and junior students when the former mentor the latter).
\end{abstract}

Keywords: pharmacists' training, accreditation standards, admission to colleges, critical thinking, teaching methods, interprofessional cooperation, clinical rotations, mentoring, Canada.

\section{INTRODUCTION}

Nowadays the role of a pharmacist is changing from the one that is expressed in collecting and distribution of information to making clinical decisions in order to become an advanced practitioner. But there are a lot of obstacles for this, e.g. pharmacists consider 
sciendo Порівняльна професійна педагогіка 8(2)/2018

Comparative Professional Pedagogy 8(2)/2018

themselves as specialists with a lack of confidence and knowledge necessary to perform a clinical role and unwillingness to take increased professional responsibility. All these facts hinder the appropriate development of a pharmacist profession. Hierarchic system of health care, not quite clear understanding of the pharmacist's role in health care organizations and society, ignoring the problem of pharmacists' confidence development in the process of their training, their inability to make clinical decisions, poor mentorship and inappropriate inner qualities are the issues that are peculiar to Ukrainian pharmacy education programs and need to be solved.

Because of the necessity for the development and restructuring of pharmacists' training programs to correspond to their increased practical role in society the experience of developed countries is of special interest. We have studied different educational models and programs of pharmacists' training in the world and found out that a vast experience belongs to Canada, where pharmacists are one of the most respected professions. Canadian institutions of higher education have optimal strategies to provide the quality of such training and thus are worth considering by Ukraine. Canada for the last decade has introduced a lot of changes concerning admission to colleges of pharmacists, assessment of students' critical thinking and teaching methods, improvement of courses content delivery, interprofessional cooperation, development of practical experimental education, mentoring programs etc. All these improvements will enhance Ukrainian system of pharmacists' training and help outline directions of further development.

\section{THE AIM OF THE STUDY}

The main idea of the present research is to study the appropriate experience of Canada in educational approaches to developing pharmacists' training in higher educational institutions with a view of prospective usage of the positive experience in the pharmaceutical educational establishments of Ukraine.

\section{THEORETICAL FRAMEWORK AND RESEARCH METHODS}

Theoretical basis for our research is a set of regulatory and legislative documents outlining the process of pharmacists' training produced at the state level as well as at the level of non-profit professional organizations such as Canadian Council of Accreditation of Pharmacy Programs, Canadian Pharmacists' Association, Association of Faculties of Pharmacy of Canada etc. Theoretical basis for the research is presented by works of M. Ackman, Z. Austin, K. B. Blake, S. Buring, G. Frankel, K. Fuller, R. Greene, M. Hind, J. Kassirer, A. Lindblad, Ch. Louizos, C. Morrison, M. Rosenthal, J. Sandars and others. The research methods used are study and review of legislative and regulatory norms, comparative analysis of Canadian and Ukrainian experience, synthesis, contrasting and generalization of the obtained data.

\section{RESULTS}

So, while characterizing provision of qualitative professional training of pharmacists it is necessary to mention that all the programs for such training are performed in strict accordance with Accreditation Standards. These standards are elaborated by the Canadian Council for Accreditation of Pharmacy Programs (CCAPP) and address First Professional Degree Doctorate of Pharmacy programs. The Standards reflect professional and educational attributes identified by CCAPP and stakeholders asessential for Canadian programs that intend to develop practicing, clinical, patient-focused pharmacists (Canadian Council for the Accreditation of Pharmacy Programs, 2018).

These Accreditation Standards embrace the philosophy that program graduates should have acquired general and special knowledge necessary to provide a basis for 
critical professional evaluations. The Standards recognize that pharmacy education of high quality depends on multiple components, including general knowledge, basic and professional sciences, and professional practice experience (Canadian Council of Accreditation of Pharmacy Programs, 2013). The pharmacy curriculum is expected to embrace the scope of contemporary practice responsibilities as well as emerging roles that ensure the rational and safe use of drugs in the individualized care of patients. CCAPP believes in the preparation of competent graduates who have the ability to be medication-therapy experts and who, together with other health care providers, can contribute to making decisions to ensure that services are effective and that the community is involved in improving the health of its residents. Consequently, pharmacy graduates must have a broad understanding of health, the factors that contribute to a healthy community, and the structure and role of the health system. As well, graduates must have the ability to manage and evaluate information, and the skills needed to advocate on behalf of individuals and the community (Canadian Council for the Accreditation of Pharmacy Programs, 2018).

One more condition necessary to provide qualitative training of pharmacists is the obligatory introduction of Doctor of Pharmacy Degree as entry to practice in all higher educational establishments providing training of pharmacists to 2020. It will provide opportunities to increase pharmacists' knowledge, improve their communication and management skills, obtain more clinical practice, develop skills of cooperation to work in professional groups. Structuring training programs for pharmacists is a great step in this direction (Ackman, \& Mysak, 2009).

Here we should also mention that in Canada everything starts with admission which is organized so that to select students possessing inborn leadership skills and those of decision making. Thus, pharmacy education in Canada is oriented onto convergent personalities who are confident and ready to take responsibilities. But the process of admission in Canada is not standardized. For example, in University of British Columbia and University of Toronto a Pharmacy College Admission Test (PCAT) and Multiple Mini Interviews (MMI) are conducted. Other universities conduct psychological tests, traditional interview, writing an essay, letter of intent or admission profile. Universities of Toronto and Waterloo demand at least two years of prerequisite courses at the level of university while others demand just one (Sandars, \& Morrison, 2007).

PCAT is a standardized test elaborated to assess knowledge, skills, abilities, aptitude, which are necessary to complete the training program. It lasts for 4 hours and consists of 5 sections with multiple answers:

- biology (anatomy, psychology, microbiology, cell and molecular chemistry);

- chemistry (basic biochemistry, organic chemistry, general chemistry);

- reading (understanding, analysis, assessment);

- counting (basic algebra, statistics, calculus);

- speaking and 2 essays.

MMI in its structure is a range of 7-12 interviews (5-8 minutes each) to assess non-academic qualities (communicative, problem-solving, critical thinking, ethical decision making) (Austin, 2004). A range of researches proved that these tests are reliable, and can be used to define students with strong interpersonal qualities to be enrolled to the program. Such a process gives an opportunity to select the best students.

One more aspect worth mentioning while considering Canadian pharmacy training is teaching strategies. A great number of activities are based on the use of theory in practice 
sciendo Порівняльна професійна педагогіка 8(2)/2018

Comparative Professional Pedagogy 8(2)/2018

and critical thinking as well as clinical reasoning, inference and decision-making (Blake, \& Madhavan, 2010). Z. Austin and others assert that assessment and self-reflection are weak points in the development of higher education and improvement of critical thinking among pharmacy students. They have conducted a research and proved that these concepts should be included into the coursework and assessment research during the curriculum.

J. Kassirer affirms that using real clinical material such as patient's history with increasing complexity that corresponds to the level of students' knowledge and the level of reasoning skills will really work out. Materials of the history must be presented in chronological order. Learners get new knowledge when they appear in context of real life situations (Rosenthal, Austin, \& Tsuyuki, 2010). For this human-patient simulation is used - a clinical teaching method that helps pharmacy students implement clinical reasoning and skills of team working. Students are given an opportunity to work with a real patient's case in a stressful environment but with a low risk, where facilitators give their feedback about their activities immediately. Such work increases their confidence, self-reflection, ability to make alternative decisions, collect clinical data. In the process of this work students are asked to give diagnosis taking into account patient's words, to examine the patient, consider laboratory and microbiological data, give a therapeutic advice, deal with emergencies etc (Association of Faculties of Pharmacy of Canada (AFPC) and Association of Deans of Pharmacy of Canada, 2010; Fuller et al., 2008). So, the best way to teach clinical reasoning is to provide students with the possibility to work with patients in medical establishments to implement new acquired knowledge in practice.

Besides, new technologies with constant access to computers and media are another fact characterizing Canadian pharmacy training. Students use more diverse resources and strategies to encourage learning than their teachers.

While elaborating coursework pharmacists' teachers consider that:

1) they cannot provide optimal educational environment for students with different expectations from the content of the course. What is more, students don't consider a teacher a provider of knowledge but as facilitator;

2) students must see clear connections of tasks with pharmacy practice;

3) collaborative work is an important part of education, as students value it;

4) students value effective, constructive feedback with the use of technologies as indispensable part of learning process in the classroom. Some pharmacy schools even demand using laptops as a tool of learning to encourage new strategies of technological education (Lindblad, Howorko, Cashin, Ehlers, \& Cox, 2011).

One more important approach to enhancement of pharmacists' education is interprofessional training. It is proved that caking care of patients in team environment has positive impact on students. Professional cooperation (according to a definition by WHO) is an approach to health protection aimed at the patient and is team-based; it underlines one's strengths and skills related to health care provision. Medicine and pharmacy are different fields but tightly interconnected. Medical students feel more confident taking patient's history while pharmacy students can analyze drug therapy better. So, in such a way they can easily cooperate to perform better care of patients (Cisneros, 2009).

M. Hind and others claim that early introduction of interpersonal learning opportunities encourage students' desire to take care of patients. And it should be introduced at the first years of studying while their social identity is not formed yet. They perceive themselves just as a part of students' community, not as pharmacists or doctors etc. That's why it is easier for them to start interprofessional cooperation. It attracts them as it is an 
opportunity to provide better care to patients, satisfy their professional interest concerning other professions in health care (Frankel, Frankel, \& Austin 2013; Frankel, Louizos, \& Austin, 2014).

Clinical experimental rotations are one more approach that should be taken into consideration by Ukrainian educators and legislators. The majority of practice programs in Ukraine are short, take place only during last years of education and do not supply enough time to convert knowledge into practical skills. Students often just observe the role of a pharmacist without active participation and that is why they cannot make responsible decisions that are related to health care. Short-term practices (2-4 weeks) are not sufficient for students to take up their role, feel comfortable in their profession, feel responsible for the patient and take an active part in educational activities (Greene, Cavell, \& Jackson, 1996).

The Canadian Council for Accreditation of Pharmacy Programs constantly pays attention to recommended increase of practice time up to 40 weeks (1600 hours). Of course, the increase of hours means the necessity to increase the number of practice bases (places). It is rather difficult for faculties to provide these places for clinical rotation because of their limited quantity and general unwillingness to accept students (because of their being busy, lack of students' confidence and independence). So, it is necessary to solve the problem at the level of state as well as curriculum to provide students with instruments necessary for successful clinical placements (Frankel, Louizos, \& Austin, 2014).

In Canada there are some strategies for providing students with valuable educational and practical rotation experience worth considering in Ukraine. The first is early involvement of students to establishments for taking care of patients. An interesting experiment was conducted by M. Ackman and others who introduced hospital rotation for second year students for them to take on a clinical role and encourage their direct activity related to patients' care such as medication history taking and evaluation of allergy reactions. Such experience encouraged students' confidence (Hind, Norman, \& Cooper, 2003).

One more strategy is experimental rotations according to which senior students teach and mentor junior students and the preceptor looks after the process.

A. Linblad and others formed clinical teaching unit model in a Canadian hospital of intensive care for five students of the fifth year of education. The model included 9 weeks of rotation ( 3 students during the first week, the others - during the fifth one). Preceptors shared their obligations with students, so that they had to take medical history, review medication, make, implement and analyze (control) treatment schemes (under the preceptor's supervision). Besides, the group that started in the first week mentored the one that started in the fifth week and reviewed their schemes of treatment before the preceptor. Students thoroughly reviewed clinical activities of their students, such as history taking and medication prescription. Preceptors and students marked out that their confidence, independence, ability to think, manage their time, their responsibility increased during the clinical teaching mode more than during a traditional mode (Hoffman, Rosenfield, \& Nasmith, 2009).

Z. Austin affirms that work aimed at patients' care must be introduced at all the stages of education in accordance with the level of students' abilities. Experimental rotation is a valuable experience of students' learning which transforms theoretical knowledge into active experience with direct care of patients (American Association of Colleges of Pharmacy, 2013).

Unfortunately, clinical resources and places for this kind of practice in Ukraine are limited but it is the state that has to solve the problem (provide a system of preceptors' support, mentorship of junior students by senior students in clinical establishments). 
Sciendo Порівняльна професійна педагогіка 8(2)/2018

Comparative Professional Pedagogy 8(2)/2018

And the last approach to enhancement of pharmacists' qualitative training is mentorship. To be a good mentor one should have the following qualities: enthusiasm, compassion, wiliness to help others (in our case to help students reach balance of their personal and professional life), be a good example to follow (Frankel, Louizos, \& Austin, 2014). Canada has a lot of researches in strategies of mentorship development, implementing and assessment. A pilot project, described by G. Frankel, Ch. Louizos and Z. Austin, is worth mentioning. It involved 3 experienced pharmacists and 3 pharmacists with the experience of clinical activities less than 18 months to define the efficiency of mentorship. According to it, a mentor and a mentee often met and discussed educational purposes and ways of their achievement. The results show that the level of their confidence and work satisfaction increased considerably.

\section{CONCLUSIONS}

So, it is clear that Canada provides professional training to pharmacy students in such a way that pharmacists are able to work with people efficiently. Pharmacists become trusted and respected members of the communities in which they work, develop skills in judgment and public relations, and provide support to students and new health providers. Pharmacists practice with compassion, empathy, and integrity and are expected to work in intra- and interprofessional teams, and be adaptable enough to work in a variety of settings. It is defined that in Canada educational outcomes established for a professional degree program in pharmacy encompass the entry-to-practice competencies specified by the appropriate licensing authority. The public is entitled to demand that the graduates of a professional degree program can demonstrate they have mastered the entry-to-practice competencies for that profession, but this does not prevent a Faculty of Pharmacy or a regulatory authority from establishing additional educational outcomes.

It has been found out that a number of techniques are used in Canada to enhance qualitative training of pharmacists: 1) constant pharmacy curriculum development which is aimed at embracing the scope of contemporary practice responsibilities as well as emerging roles that ensure the rational and safe use of drugs in the individualized care of patients; 2) strict admission of students to pharmacy colleges that is organized so that to select students possessing inborn leadership skills and those of decision making; 3) the use of teaching strategies of theory in practice, critical thinking, clinical reasoning, inference and decision-making; 4) professional cooperation between medical and pharmacy students that is a team-based approach to health protection aimed at the patient; it underlines one's strengths and skills related to health care provision; 5) two kinds of clinical experimental rotations - early involvement of students to establishments for taking care of patients and rotations of both senior and junior students when the former mentor the latter; 6) qualitative and effective mentorship.

It has been defined that appropriate analysis and implementation of these techniques in Ukrainian pharmaceutical educational establishments will enhance the quality of pharmacists' training.

The further step of our research is to analyze different aspects of accreditation standards for first to entry degree in pharmacy in terms of its planning, provision, implementation and control.

\section{REFERENCES}

1. Ackman, M. L., \& Mysak, T. M. (2009). Structuring an early clinical experience for pharmacy students: lessons learned from the hospital perspective. Canadian Journal of Hospital Pharmacy, 62 (4), 320-325. 
2. American Association of Colleges of Pharmacy. (2013). Commission to Implement Change in Pharmaceutical Education. Entry-level education in pharmacy: a commitment to change. Retrieved from http:/www.aacp.org/resources/historicaldocuments/Documents/ COMMISSPOSPAPER3.pdf.

3. Association of Faculties of Pharmacy of Canada (AFPC) and Association of Deans of Pharmacy of Canada (2010). Position Statement and Joint Resolution on the Doctor of Pharmacy for the First Professional Degree at Universities in Canada. Retrieved from https://www.afpc.info/sites/default/files/AFPC_ADPC_PharmD_Position_Statement_Resol ution_Sept_2010.pdf.

4. Austin, Z. (2004). Learning styles of pharmacists: impact on career decisions. Practice Patterns and Teaching Methods. Pharmacy Education, 4 (1), 13-22.

5. Blake, K. B, \& Madhavan, S. S. (2010). Perceived barriers to provision of medication therapy management services and the likelihood of a pharmacist to work in a pharmacy that provides MTMS. Annals of Pharmacotherapy, 44 (3), 424-431.

6. Canadian Council for the Accreditation of Pharmacy Programs (2018). Accreditation Standards for Canadian First Professional Degree in Pharmacy Programs. Toronto: CCAPP.

7. Cisneros, R. M. (2009). Assessment of critical thinking in pharmacy students. American Journal of Pharmaceutical Education, 73 (4), 66-72.

8. Frankel, G, \& Austin, Z. (2013). Responsibility and confidence: identifying barriers to advanced pharmacy practice. Canadian Pharmacists Journal, 146 (3), 155-161.

9. Frankel, G., Louizos, Ch., \& Austin, Z. (2014). Canadian educational approaches for the advancement of pharmacy practice. American Journal of Pharmaceutical Education, 78 (7), 143.

10. Fuller, K., Maniscalco-Feichtl, M., Droege, M. (2008). The role of the mentor in retaining junior pharmacy faculty members. American Journal of Pharmacy Education, $72(2), 41-49$.

11. Greene, R. J., Cavell, G. F., \& Jackson, S. H. (1996). Interprofessional clinical education of medical and pharmacy students. Medical Education, 30 (2), 129-133.

12. Hind, M., Norman, I., \& Cooper, S. (2003). Interprofessional perceptions of health care students. Journal of Interprofessional Care, 17 (1), 21-34.

13. Hoffman, S., Rosenfield, D., \& Nasmith, L. (2009). What attracts students to interprofessional education and other health care reform initiatives? Journal of Allied Health, 38 (3), 75-78.

14. Lindblad, A. J., Howorko, J. M., Cashin, R. P., Ehlers, C. J., \& Cox, C. E. (2011). The development and evaluation of a student pharmacist clinical teaching unit utilizing peer assisted learning. Canadian Journal of Hospital Pharmacy, 64 (6), 446-450.

15. Rosenthal, M., Austin, Z., \& Tsuyuki, R. T. (2010). Are pharmacists the ultimate barrier to pharmacy practice change? Canadian Pharmacists Journal, 143 (1), 37-42.

16. Sandars, J., \& Morrison, C. (2007). What is the net generation? The challenge for future medical education. Medical Teacher, 29 (2-3), 85-88.

17. The Canadian Council of Accreditation of Pharmacy Programs (2013). Accreditation standards and guidelines for the first professional degree in pharmacy programs. Retrieved from http://www.ccapp-accredit.ca/site/pdfs/university/CCAPP_accred_standards_degree_2012.pdf. 